\title{
Expanding Access to and Ensuring Equity in the Benefits of Remote Work Following the COVID- 19 Pandemic
}

\author{
$\underline{\text { Ashley E. Orr }}^{1}$, Tamara Savage ${ }^{2}$ \\ ${ }^{1}$ Heinz College of Information Systems and Public Policy, Carnegie Mellon University, Pittsburgh, \\ Pennsylvania USA \\ 2Department of Engineering and Public Policy, Carnegie Mellon University, Pittsburgh, Pennsylvania USA \\ https://doi.org/10.38126/ISPG180413 \\ Corresponding author: aorr@cmu.edu \\ Keywords: Remote work; telework; work-from-home; worker equity; labor economics
}

\begin{abstract}
Executive Summary: The COVID-19 pandemic has dramatically increased the number of people working from home, with over $50 \%$ of employees working remotely during 2020 . With the current popularity of remote work and the high prevalence of high-speed internet, video conferencing technology, remote collaboration tools, email, and other technologies, remote work will likely remain common after the pandemic ends and offices fully reopen. There are many benefits of remote work, including increased productivity, better work-life balance, reduced commute time and traffic congestion, decreased emissions, and cost savings for employees and employers. However, access to the privilege of remote work is unevenly distributed across occupations and socioeconomic groups. Among those who can work remotely, there may be disparities in performance appraisals and promotions compared to inperson workers. Congress has a unique opportunity to address these inequities via expansion of the Telework Enhancement Act, which currently covers federal government employees, to include firms in the private sector. This Act enables all employees whose jobs can be performed remotely to do so and mandates that remote workers and in-person workers be treated the same for the purposes of training, performance appraisal, and promotion.
\end{abstract}

\section{Problem statement}

The COVID-19 pandemic has dramatically increased the number of people working from home, with approximately $50 \%$ of employed persons working remotely over the last year (US Bureau of Labor Statistics 2021; Mateyka, Rapino, and Landivar 2012; Brenan 2020). The adoption of technologies such as online collaboration tools, web conferencing, high speed internet, and automation has further enabled and accelerated the creation of work infrastructure to allow for remote work (Davis, Ghent, and Gregory 2021). Remote work is now popular with both employees and employers, with $83 \%$ of executives saying that the shift to remote work has been successful for their company and 84\% of employees expressing a desire to work from home at least one day per week post-pandemic (PricewaterhouseCoopers 2021). There are many benefits of remote work, such as increased productivity, better work-life balance, reduced commute time and congestion, decreased emissions, and cost savings for employees and employers. Given recent technology and workforce trends, remote work will likely remain common after the pandemic ends and offices fully reopen. However, there are differences in access to remote work options across occupational, socioeconomic, and demographic groups. There are also potential disparities in the perception, assessment, and promotion of remote employees that, if left unaddressed by policy, may risk unequally distributing the benefits of remote work. Policies are needed to expand access to the economic, social, and environmental benefits of remote work while jointly prioritizing the equitable distribution of these benefits. 


\section{Benefits of remote work}

Remote work provides a variety of benefits for employees, employers, and the environment. Benefits include employees saving time and money avoiding long, stressful, and costly commutes; reduced congestion, motor vehicle accidents, and personal automobile emissions; reduced office costs for firms and businesses; increased productivity and worker retention; reduced microaggressions and bias; and the ability for employees to better balance work and family (DeVerter 2020; Rosenberg 2020; Shilling and Waetjen 2020; Tulshyan 2021; PricewaterhouseCoopers 2021; Pringle 2020; Maurer 2020). The benefits of remote work seen in previous academic research were replicated during the pandemic (Barrero, Bloom, and Davis 2021; Brenan 2020; Maurer 2020; PricewaterhouseCoopers 2021; Shilling and Waetjen 2020).

With respect to productivity and work-life balance, experimental firm-level evidence shows increases in productivity (13\% performance increases) of work from home employees (Bloom et al. 2015), with particular improvements in the performance and well-being of working mothers and caregivers (Sherman 2020). Eliminating the diseconomies of commuting and traffic congestion also has productivity implications, as employees with longer commute times have higher rates of absenteeism and late arrivals, which has negative productivity implications for employers (van Ommeren and Gutierrez 2011). Access to employment centers, and thus commute times, also vary within the population, with Black workers having on average longer commutes (University of Chicago 2014). As commute time cuts into workers' time remaining for leisure, long amounts of time spent commuting may result in the increased potential for allocating time unproductively at work (Ross and Zenou 2008). By eliminating the need for a commute, remote work frees up workers' leisure time and has the potential to increase productivity of the firm by reducing absences (with estimated declines by $15-20 \%$ as in van Ommeren and Gutierrez 2011), late starts, and unproductive uses of working time.
The availability of remote work also provides opportunities for greater labor market inclusion of historically disadvantaged groups. These groups include persons with disabilities (Eloise 2021; Faragher 2020; Government of Ireland 2021; GAO 2010), workers in underperforming and rural labor markets (Shimer 2007; Government of Ireland 2021), and mothers and other caregivers (Government of Ireland 2021). A key mechanism for greater labor market inclusion is that remote work reduces or eliminates the need for a commute. Men empirically are more likely to travel farther for work (women's commutes are $33 \%$ shorter in OECD countries) and as a result, women are more likely to forgo higher paying positions for employment roles with shorter commutes and greater flexibility (Goldin 2014; Le Barbanchon, Rathelot, and Roulet 2019). Recent research has indicated that commuting preferences explain substantial portions (21\%) of the gender wage gap in the US (Liu and Su 2020), which indicates that eliminating commuting considerations among workers may have important implications for reducing wage inequality. Empirically, workers' job search behavior implies strong preferences for short commutes (Marinescu and Rathelot 2018). Further, soliciting the preferences of workers found the benefits of flexible work arrangements are so important to job applicants that they are actually willing to accept lower wages (forgoing $8 \%$ of wages) for teleworking privileges (Mas and Pallais 2017).

\section{Current and potential problems}

Although there are many benefits of remote work, the first problem arises with regard to differential access to remote employment opportunities across socioeconomic groups. For example, Figures 1 and 2 show that there are disparities among those who worked remotely due to the pandemic along racial and educational attainment groups ${ }^{1}$. While the COVID-19 pandemic did cause drastic increases (300$400 \%$ by some estimates) in remote work, studies have found that the occupations and industries that account for the majority of those increases were those which had larger proportions of their workforce partially working remotely prior to the pandemic (Adams-Prassl et al. 2020). About 40\% of jobs can be performed remotely, and the people who

\footnotetext{
${ }_{1}^{1}$ These figures depict those who are newly working remotely due to the pandemic and do not include those who had previously worked from home, which in other studies is estimated to be around 10\% (Mateka, Rapino, and Landivar 2012; Gariety and Shaffer 2007).
} 


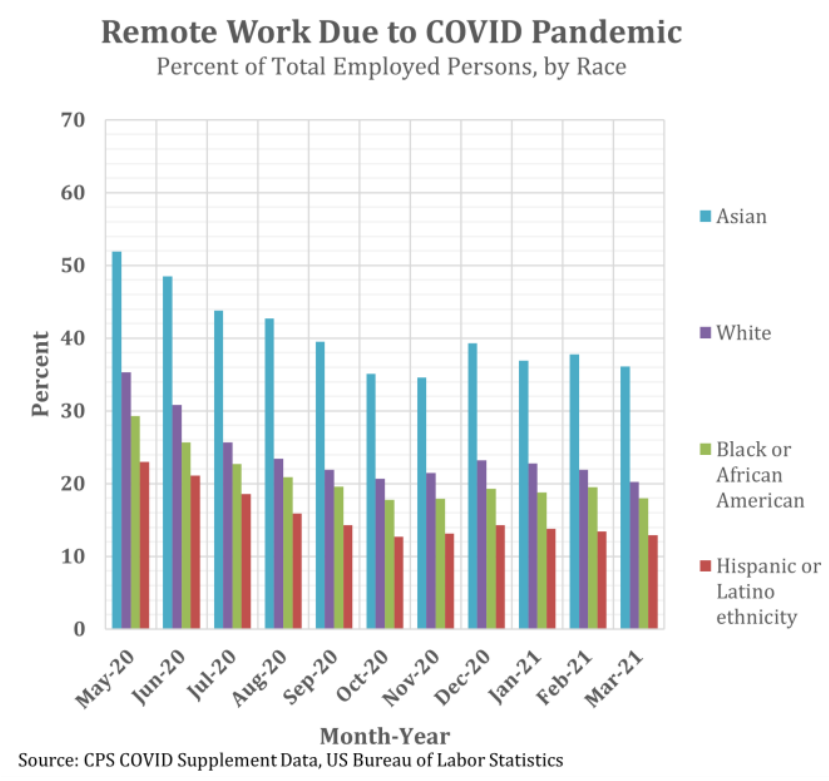

Figure 1: Remote work due to COVID-19 pandemic, percent of total employed persons, by race (US Bureau of Labor Statistics 2021)

have these jobs are more likely to be white or Asian and receive higher wages (Greenfield 2021). In May of 2020 , more than $50 \%$ of Asian employees and approximately $35 \%$ of white employees worked remotely, but just $29 \%$ of Black and $23 \%$ of Hispanic workers were able to do so (Figure 1). In the UK, onefifth of disabled workers who requested to work remotely, be furloughed, or be redeployed had their requests denied during the pandemic, as employers had discretion to deny these requests (Faragher 2020).

The second key problem associated with remote work arises due to differential perception, assessment, and promotion of remote workers and in-person workers, which risks exacerbating existing inequalities. In one study, employees who worked remotely were only half as likely to be promoted as in-person employees (Bloom et al. 2015). Women, especially mothers, are more likely to suffer from "flexibility stigma" after taking advantage of flexible work policies (Chung 2020). Using flexibility benefits leads to lower promotion scores, with mothers often the main users of flexibility arrangements (Fernandez-Lozano and Martinez-Pastor 2020). Studies have found that those who engage in "face time" (in-person work) get better performance appraisals (Elsbach, Cable, and Sherman 2010) and have shorter time to promotion (Munck 2001). Men who requested family leave also suffered from

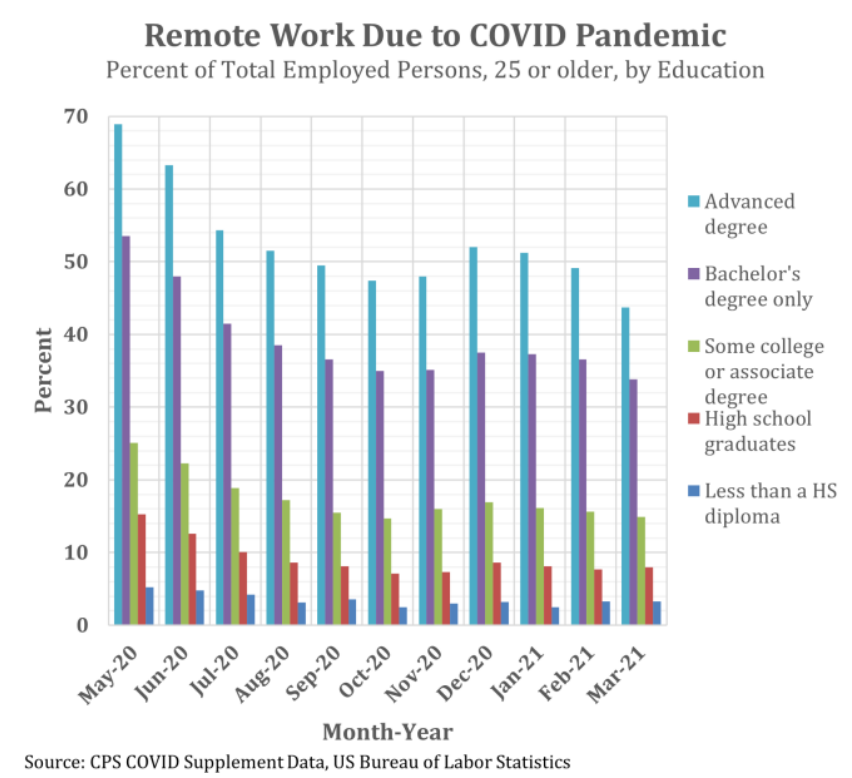

Figure 2: Remote work due to COVID-19 pandemic, percent of total employed persons, by education (US Bureau of Labor Statistics 2021)

flexibility stigma and were more likely to be demoted or downsized (Rudman and Mescher 2013), indicating that it is not just women who suffer from this stigma. A study by Mercer (2014) found that in order for flexible schedules and maternity leave to not negatively impact women's performance ratings and promotion, the employer needed to actively counter stigma associated with using the programs and widely encourage both men and women to use the programs. If certain demographic groups, such as women with children or disabled persons, are more likely to work remotely, and remote workers are less likely to be promoted, this creates a new margin of inequity which disproportionately harms those already disadvantaged in the labor market. In addition, this may make employers liable to discrimination lawsuits (Greenfield 2021; Zeidner 2020).

\section{Current legislation}

US labor laws do not currently include a right to work remotely for private employers; the decision to offer remote work rests solely with the employer. Under the Fair Labor Standards Act (1938), enforced by the Equal Employment Opportunity Commission, employers can offer remote work to employees as long as they maintain an accurate record of hours worked. The Equal Employment Opportunity Commission administers and enforces the Fair Labor Standards Act, the Equal Pay Act (1963), and the 
Americans with Disabilities Act (1990). These laws cover pay equality on the basis of race, color, national origin, religion, sex, age, disability, sexual orientation, gender identity, and genetic information and provide for the reasonable accommodation of disabled employees. However, many federal government employees are authorized to work remotely under the Telework Enhancement Act (2010).

The Telework Enhancement Act (The Act) requires each executive agency to establish and implement a policy under which all federal employees whose jobs can be performed remotely are authorized to telework. It also requires both managers and employees to complete training and create a written telework agreement before they are allowed to telework. The Act provides a framework for federal agencies to better leverage technology and maximize the use of telework (OPM n.d.). The Act directs the head of each agency to ensure that "teleworkers and non-teleworkers are treated the same for the purposes of periodic appraisals of job performance of employees; training, rewarding, reassigning, promoting, reducing in grade, retraining, and removing employees; and work requirements" (Telework Enhancement Act 2010, § 6503-3). In 2018, 51\% of eligible federal employees worked remotely, equaling $22 \%$ of all federal employees (OPM 2020). Agencies reported many benefits, including improved performance and productivity, improved recruitment and retention, reduced employee absences, accommodation of temporary and long-term medical needs, cost savings on rent, and reduced energy use (OPM 2020), findings which were in line with the aforementioned academic research.

\section{Option 1: Extend the Telework Enhancement Act to cover all firms in the US}

\section{i. Advantages}

This would make all employees (whose work can be performed remotely) eligible to take advantage of remote work, which would expand access to the benefits of remote work for both employees and employers. This should enable more women, people of color, and people with disabilities to enjoy these benefits. This would also address potential disparities in promotion, performance appraisal, and training opportunities by proactively protecting those who choose to work remotely so they are not being put at a disadvantage compared to their peers who work in-person. This option would reduce the likelihood of exposure to discrimination claims for firms. Since this option extends an existing piece of legislation, it is less risky and will require less effort than developing a new policy.

\section{ii. Disadvantages}

Enforcement may be difficult, as this policy would likely be enforced internally through human resources departments and externally through lawsuits. It may be politically difficult to mandate that private companies uniformly adopt this government workforce policy. There may be compliance costs for companies that have not already invested in the infrastructure and technology needed to enable remote work and additional costs associated with training employees and managers. However, the aforementioned economic forces and employee preferences indicate that many companies have already partially adopted remote work or will be incentivized to do so by their competitors.

\section{Option 2: Include "remote workers" as a protected class of workers covered by federal employment non-discrimination laws}

Given the nonpecuniary benefits associated with remote work, one potential risk of its expansion is unequal treatment between remote and non-remote employees within the same establishments who perform nearly identical jobs requiring similar skill and effort. Federal employment laws, such as the Fair Labor Standards Act, the Equal Pay Act, and the Civil Rights Act, currently prohibit workplace discrimination for protected classes such as sex, race, disability, national origin, or religion. This rise in remote work may call for updates to the legislation to include language with respect to all formats of work.

\section{i. Advantages}

This ensures workers who perform the same jobs in a remote or non-remote modality are paid equally. That is, it has the potential to prohibit a new margin of wage inequality. Enforcement of such a policy expansion would be handled through the existing Equal Employment Opportunity Commission, with risk of litigation incentivizing compliance.

\section{ii. Disadvantages}

While this policy addresses one facet of the equity concerns associated with the rise of remote work, 
given the evidence presented above, this margin is unlikely to be the most consequential for worker equity. For instance, it does not address differences in assessment standards between remote and nonremote employees, access to within-firm promotion ladders, and differential access to the privilege of working remotely among socioeconomic groups and across occupations. Complexities could arise when addressing differential cost of living across geographies. Finally, this policy may be challenged as work modality is inherently different from the nature of the categories included in the current list of protected classes in the US.

\section{Consequences of inaction}

Even once public health concerns ease, pre-pandemic trends in remote work will likely be accelerated as some workers and firms continue to reap the benefits without pandemic-related drawbacks, e.g., childcare closures and stay-at-home mental health repercussions. Left unaddressed by policy, many of the aforementioned benefits will continue, but so will the current and potential problems, which may exacerbate existing inequalities and unevenly distribute benefits. More highly educated workers

\section{References}

Adams-Prassl, Abi, Teodora Boneva, Marta Golin, and Christopher Rauh. 2020. "Work Tasks That Can Be Done From Home: Evidence on the Variation within and across Occupations and Industries." IZA Institute for Labor Economics, IZA DP, no. 13374 (June): 1-62.

Americans with Disabilities Act, 42 U.S.C. § 12101 (1990).

Barrero, Jose Maria, Nicholas Bloom, and Steven J. Davis. 2021. "Why Working from Home Will Stick." National Bureau of Economic Research Working Paper No. 28731, April 2021. https://www.nber.org/papers/w28731.

Bloom, Nicholas, James Liang, John Roberts, and Zhichun Jenny Ying. 2015. "Does Working from Home Work? Evidence from a Chinese Experiment." The Quarterly Journal of Economics, 130 (1): 165-218. https://doi.org/10.1093/qje/qju032.

Brenan, Megan. 2020. "COVID-19 and Remote Work: An Update.” Gallup.com. Gallup, October 13, 2020. https://news.gallup.com/poll/321800/covidremote-work-update.aspx.

Chung, Heejung. 2020. "Gender, Flexibility Stigma and the Perceived Negative Consequences of Flexible Working in the UK." Social Indicators Research 151 (2): 521-45. https://doi.org/10.1007/s11205-018-2036-7. with predominantly higher-paid, office-related occupations will reap the majority of the benefits, while concurrent unchecked workplace stigmas associated with flexibility run the risk of exacerbating inequities in performance appraisal and promotional potential. Workers without access to remote work will be unlikely to gain access to it without seeking change in employment. While in-person workers may have seen congestion and commute reductions during the pandemic, they will likely see increases in commute time as non-work and in-person work travel resumes.

\section{Policy recommendation and conclusions}

We recommend Option 1: Legislation to expand the coverage of the Telework Enhancement Act to private firms. Adopting the provisions within will both expand access to the benefits of remote work and proactively address the disadvantages caused by remote work to historically disadvantaged groups. We believe this is the best policy option to take advantage of recent technology, innovation, and workforce trends and make the future of work more inclusive and equitable.

Cristea, Ioana C., and Paul M. Leonardi. 2019. “Get Noticed and Die Trying: Signals, Sacrifice, and the Production of Face Time in Distributed Work." Organization Science 30 (3): 552-72. https://doi.org/10.1287/orsc.2018.1265.

U.S. Bureau of Labor Statistics. 2021. "Data Tables (XLSX)." U.S. Bureau of Labor Statistics. Accessed April 12, 2021.

https://www.bls.gov/cps/effects-of-thecoronavirus-covid-19-pandemic.htm.

Davis, Morris A., Andra C. Ghent, and Jesse M. Gregory. 2021. "The Work-from-Home Technology Boon and Its Consequences." National Bureau of Economic Research Working Paper No. 28461, Feb. 2021.

https://doi.org/10.3386/w28461.

DeVerter, Jeff. 2020. "In Defense Of Remote Work.” Forbes. Forbes Magazine, December 2, 2020. https://www.forbes.com/sites/forbestechcounci 1/2020/12/02/in-defense-of-remotework/?sh=519eff06144a.

National Archives and Records Administration. n.d "EEO Terminology." National Archives and Records Administration. Accessed April 17, 2021. https://www.archives.gov/eeo/terminology.html 
Eloise, Marianne. 2021. "We Still Need Accommodations." The Cut, February 4, 2021. https://www.thecut.com/2021/02/pandemicwork-disability-accommodations.html.

Elsbach, Kimberly D., Dan M. Cable, and Jeffrey W. Sherman. 2010. "How Passive 'Face Time' Affects Perceptions of Employees: Evidence of Spontaneous Trait Inference." Human Relations 63 (6): 735-760. https://doi.org/10.1177/0018726709353139.

Equal Pay Act, 29 U.S.C. § 206(d) (1963).

Fair Labor Standards Act, 29 U.S.C. § 203 (1938).

Fernandez-Lozano, Irina, and Juan-Ignacio MartinezPastor. 2020. "The Hidden Cost of Flexibility: A Factorial Survey Experiment on Job Promotion." European Sociological Review 36 (2): 265-283. https://doi.org/10.1093/esr/jcz059.

Faragher, Jo. 2020. "A Fifth of Disabled Workers Had Work from Home Requests Turned down during Pandemic." Personnel Today. DVV Media International, November 23, 2020.

https://www.personneltoday.com/hr/a-fifth-ofdisabled-workers-had-covid-work-from-homerequests-turned-down/.

Gariety, Bonnie Sue, and Sherrill Shaffer. 2007. "Wage differentials associated with working at home." Monthly Labor Review (March): 61-67. https://www.bls.gov/opub/mlr/2007/03/art5fu ll.pdf

Goldin, Claudia. 2014. "A Grand Gender Convergence: Its Last Chapter." The American Economic Review 104 (4): 1091-1119.

http://doi.org/10.1257/aer.104.4.1091.

Government Accountability Office. 2010. "Highlights of a Forum: Participant-Identified Leading Practices That Could Increase the Employment of Individuals with Disabilities in the Federal Workforce." U.S. Government Accountability Office: GA0-11-81SP.

https://www.gao.gov/products/gao-11-81sp.

Government of Ireland. 2021. "Making Remote Work: National Remote Work Strategy." Government of Ireland, Department of Enterprise, Trade and Employment, January 15, 2021. https://enterprise.gov.ie/en/Publications/Makin g-Remote-Work.html.

Greenfield, Rebecca. 2021. "Work from Home Has the Power to Advance Equality or Set It Back." Bloomberg.com. Bloomberg Businessweek, January 27, 2021.

https://www.bloomberg.com/news/articles/202 1-01-27/work-from-home-remote-work-couldadvance-or-set-back-equality.
Jones, Jeffrey M. 2020. "U.S. Remote Workdays Have Doubled During Pandemic." Gallup.com. Gallup, August 31, 2020.

https://news.gallup.com/poll/318173/remoteworkdays-doubled-during-pandemic.aspx.

Le Barbanchon, Thomas, Roland Rathelot, and Alexandra Roulet. 2021. "Gender Differences In Job Search: Trading Off Commute Against Wage." The Quarterly Journal of Economics 136, no. 1: 381426.

https://doi.org/10.1093/qje/qjaa033.

Liu, Sitian and Su, Yichen. 2020. "The Geography of Jobs and the Gender Wage Gap." FRB of Dallas Working Paper No. 2028 (October): 1-66. http://dx.doi.org/10.24149/wp2028.

Mateyka, Petr J., Melanie Rapino, and Liana Christin Landivar. 2012. "Home-Based Workers in the United States: 2010," U.S. Census Bureau, Current Population Reports.

https://www.census.gov/prod/2012pubs/p70132.pdf

Marinescu, Ioana and Roland Rathelot. 2018. "Mismatch Unemployment and the Geography of Job Search." American Economic Journal: Macroeconomics, 10(3):42-70.

http://doi.org/10.1257/mac.20160312.

Mas, Alexandre, and Amanda Pallais. 2017. "Valuing Alternative Work Arrangements." American Economic Review, 107 (12): 3722-59.

https://doi.org/10.1257/aer.20161500.

Maurer, Roy. 2020. "Study Finds Productivity Not Deterred by Shift to Remote Work." SHRM.org. Society for Human Resource Management, September 16, 2020.

https://www.shrm.org/hr-today/news/hrnews/Pages/Study-Productivity-Shift-RemoteWork-COVID-Coronavirus.aspx.

Mercer. 2014. "Well-Intended Gender Diversity Efforts Not Moving the Needle." Mercer, November 14, 2014. https://www.mercer.us/ourthinking/healthcare/well-intended-genderdiversity-efforts-not-moving-the-needle.html.

Munck, Bill. 2001. "Changing a Culture of Face Time." Harvard Business Review, 79(10):125-131.

Office of Personnel Management. n.d. "Telework Legislation: Telework Enhancement Act." Telework.gov. U.S. Office of Personnel Management. Accessed April 29, 2021.

https://www.telework.gov/guidancelegislation/telework-legislation/teleworkenhancement-act/.

Office of Personnel Management. 2020. "Status of Telework in the Federal Government: Report to Congress Fiscal Year 2018." OPM.gov. March 2020. https://www.telework.gov/reportsstudies/reports-to-congress/2019-report-tocongress.pdf. 
Phillips, David C. "Do Low-Wage Employers Discriminate Against Applicants with Long Commutes?: Evidence from a Correspondence Experiment." The Journal of Human Resources 55, no. 3: 864901.

https://doi.org/10.3368/ihr.55.3.1016-8327R.

PricewaterhouseCoopers. 2021. "Business Needs a Tighter Strategy for Remote Work." $P w C$, January 12, 2021.

https://www.pwc.com/us/en/library/covid19/us-remote-work-survey.html.

Mark Pringle. 2020. "Testimony of Mark Pringle, Senior Vice President, Corporate Real Estate, Global Facilities, and Environment, Health, \& Safety, Dell Technologies, Before the United States Senate Committee on Environment \& Public Works." July 29, 2020.

https://www.epw.senate.gov/public/ cache/files /d/b/dbac8aeb-21ff-4851-bf5fcb46e27f8b53/8A29868500579E6F23DFC3951 9D194E4.07.29.2020-pringle-testimony.pdf

Michelle B. Rosenberg (Acting Director, Strategic Issues, GAO). 2020. "Federal Telework: Key Practices That Can Help Ensure the Success of Telework Programs." Testimony Before the Subcommittee on Regulatory Affairs and Federal Management, Committee on Homeland Security and Governmental Affairs, U.S. Senate. November 18, 2020.

https://www.hsgac.senate.gov/imo/media/doc/ Michelle\%20Rosenberg\%20Testimony\%20\%20GA01.pdf

Ross, Stephen L, and Yves Zenou. 2008. "Are Shirking and Leisure Substitutable? An Empirical Test of Efficiency Wages Based on Urban Economic Theory." Regional Science and Urban Economics 38, no. 5: 498-517. https://doi.org/10.1016/j.regsciurbeco.2008.05. $\underline{009}$.
Rudman, Laurie A., and Kris Mescher. 2013. "Penalizing Men Who Request a Family Leave: Is Flexibility Stigma a Femininity Stigma?" Journal of Social Issues 69 (2): 322-40. https://doi.org/10.1111/josi.12017.

Sherman, Eliot L. 2020. "Discretionary Remote Working Helps Mothers Without Harming Non-Mothers: Evidence from a Field Experiment." Management Science 66, no. 3: 1351-1374. https://doi.org/10.1287/mnsc.2018.3237

Shilling, Fraser, and David Waetjen. 2020. "Special Report (Update): Impact of COVID19 Mitigation on Numbers and Costs of California Traffic Crashes." Road Ecology Center UC Davis, Apr. 2020. https://roadecology.ucdavis.edu/files/content/p rojects/COVID CHIPs_Impacts updated 415.pdf

Shimer, Robert. 2007. "Mismatch." The American Economic Review 97, no. 4 (2007): 1074-1101. https://doi.org/10.1257/aer.97.4.1074.

Telework Enhancement Act, 5 U.S.C. § 6501 (2010).

Tulshyan, Ruchika, 2021, "Return to Office? Some Women of Color Aren't Ready," The New York Times, June 23, 2021.

https://www.nytimes.com/2021/06/23/us/retu rn-to-office-anxiety.html

University of Chicago. 2014. "Longer Commutes Disadvantage African-American Workers." ScienceDaily. Accessed July 13, 2021. www.sciencedaily.com/releases/2014/02/1402 15122416.htm.

van Ommeren, Jos N, and Eva Gutiérrez-i-Puigarnau. 2011. "Are Workers with a Long Commute Less Productive? An Empirical Analysis of Absenteeism." Regional Science and Urban Economics 41, no. 1: 1-8. http://dx.doi.org/10.1016/j.regsciurbeco.2010.0 7.005.

Zeidner, Rita. 2020. “Coronavirus Makes Work from Home the New Normal." Society for Human Resource Management, March 21, 2020.

https://www.shrm.org/hr-today/news/allthings-work/pages/remote-work-has-becomethe-new-normal.aspx.

Ashley E. Orr is a Ph.D. Student and National Science Foundation Graduate Research Fellowship Program Fellow at Carnegie Mellon University's Heinz College. Ashley researches at the intersection of labor economics, urban economics, and public policy. A first-generation college graduate, Ashley earned a Master of Philosophy in Economics from the University of Oxford, England, where she studied funded by the Rhodes Scholarship. She also holds a BS in Mathematics and BA in Economics from Youngstown State University.

Tamara Savage is a Ph.D. Candidate in the Department of Engineering and Public Policy at Carnegie Mellon University. Her work is at the intersection of emerging technologies and public policy, and her dissertation research is focused on improving technology forecasting by including policy, economic, and social factors in forecasts. Tamara has previously worked for the federal government and in industry. She holds a BS in Engineering and Literature from Harvey Mudd College. 


\section{Acknowledgements}

This material is based upon work supported by the National Science Foundation Graduate Research Fellowship Program under Grant No. DGE1745016.

\section{Disclaimer}

Any opinions, findings, and conclusions or recommendations expressed in this material are those of the authors and do not necessarily reflect the views of the National Science Foundation. 